\title{
PRENATAL GENTLE YOGA PADA IBU HAMIL TERHADAP BERAT BADAN BAYI BARU LAHIR
}

\section{PRENATAL GENTLE YOGA IN PREGNANT MOTHERS TOWARDS NEWBORN BABY WEIGHT}

\author{
Eggy Widya Larasati ${ }^{\varpi_{1}}$, Mustika Pramestiyani² \\ ${ }^{1}$ Universitas Binawan, Jl. Raya Kalibata No 25, Jakarta Timur, DKI Jakarta. Indonesia \\ ${ }^{2}$ Politeknik Kesehatan Kementerian Kesehatan Jayapura, JI.Padang Bulan II, Hedam, Papua. Indonesia \\ Correspondence Email : eggy@binawan.ac.id
}

\begin{abstract}
ABSTRAK
Proses kehamilan merupakan masa perubahan pada wanita banyak menimbulkan stress, sehingga membutuhkan pelayanan antenatal yang berkesinambungan. Salah satu dari pelayanan antenatal yang diberikan adalah prenatal gentle yoga. Penelitian ini bertujuan untuk mengetahui hubungan prenatal gentle yoga pada ibu hamil terhadap berat badan bayi baru lahir di Klinik RK. Jenis penelitian adalah kuantitatif dengan dessain quasi - eksperimen yang bersifat two group postest. Populasi penelitian adalah ibu hamil primigravida yang memeriksakan kehamilan trimester III, melakukan prenatal gentle yoga dan melahirkan pada bulan Mei-Juli 2021. Teknik pengambilan sampel menggunakan purposive sampling dengan sampel sebanyak 50 sampel (25 intervensi dan 25 kontrol). Uji statistik menggunakan spearman's rho dan mann whitney. Hasil penelitian menunjukkan ada hubungan antara prenatal gentle yoga dengan berat badan lahir dengan nilai $p=0,004<\alpha=0,05$, nilai uji Mann Whitney perbedaan berat badan bayi baru lahir pada ibu yang melakukan prenatal gentle yoga dibandingkan yang tidak melakukan prenatal gentle yoga dengan nilai $p=0,004<\alpha=0,05$ untuk berat badan lahir.
\end{abstract}

Kata Kunci : ibu hamil; prenatal gentle yoga; berat badan lahir

\begin{abstract}
Pregnancy is a period of change in women causing a lot of stress, so it requires continuous antenatal care. One of the antenatal services provided is prenatal gentle yoga. This study aims to determine the relationship of prenatal gentle yoga in pregnant women to the weight of newborns at the RK Clinic. This type of research is quantitative with a quasi-experimental design that is a two group posttest. The study population was primigravida pregnant women who had their third trimester of pregnancy checked, did prenatal gentle yoga and gave birth in May-July 2021. The sampling technique used purposive sampling with a sample of 50 samples (25 interventions and 25 controls). Statistical test using spearman's rho and mann whitney. The results showed that there was a relationship between prenatal gentle yoga and birth weight with $p$ value $=0.004<\alpha=0.05$, the value of the Mann Whitney test was the difference in the weight of newborns in mothers who did prenatal gentle yoga compared to those who did not do prenatal gentle yoga with $p$ value $=0.004<=0.05$ for birth weight .
\end{abstract}

Keywords: pregnant women; prenatal gentle yoga; birth weight

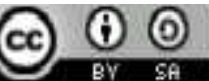

Jurnal SMART Kebidanan is licensed under a Creative Commons Attribution-ShareAlike 4.0 International License 


\section{PENDAHULUAN}

Survey Demografi dan Kesehatan Indonesia tahun 2017 menyebutkan bahwa Angka Kematian Ibu (AKI) mencapai 359 per 100.000 kelahiran hidup. Angka tersebut masih jauh dari target Millenium Development Goals (MDG's) 2015 yaitu 102 per 100.000 kelahiran hidup ditahun 2015. Hasil Supas tahun 2015 memperlihatkan angka kematian ibu tiga kali lipat dibanding target MDG's. Upaya percepatan penurunan AKI dilakukan dengan menjamin agar setiap ibu mampu mengakses pelayanan kesehatan ibu yang berkualitas, seperti pelayanan kesehatan ibu hamil, pertolongan persalinan oleh tenaga kesehatan terlatih di fasilitas pelayanan kesehatan, perawatan pasca persalinan bagi ibu dan bayi, perawatan khusus dan rujukan jika terjadi komplikasi, dan pelayanan keluarga berencana termasuk KB pasca persalinan (Profil Kesehatan Indonesia, 2019)

Penyebab utama angka kematian ibu di Indonesia tahun 2019 terbanyak adalah perdarahan (1.280 kasus), hipertensi dalam kehamilan (1.066 kasus), infeksi (207 kasus). Dari penyebab angka kematian ibu dan angka kematian bayi tersebut sebenarnya petugas kesehatan dapat melakukan upaya pencegahan yaitu melalui pelayanan antenatal yang intensif dan holistik sehingga ibu dan bayi sehat sampai proses kelahiran (Aulia dkk., 2013).

Upaya kesehatan ibu yang diterapkan oleh pemerintah yaitu melakukan pelayanan kesehatan ibu hamil, pelayanan tetanus bagi wanita subur dan ibu hamil, pemberian tablet $\mathrm{FE}$, pelayanan kesehatan ibu bersalin, pelayanan kesehatan ibu nifas, Puskesmas melaksanakan kelas ibu hamil dan Program Perencanaan Persalinan dan Pencegahan Komplikasi (P4K), pelayanan kontrasepsi/KB dan pemeriksaan HIV dan Hepatitis B.

Pelayanan antenatal adalah pelayanan kesehatan oleh tenaga profesional untuk ibu selama masa kehamilan, persalinan dan nifas serta mengusahakan bayi yang dilahirkan sehat, memantau kemungkinan adanya risiko-risiko kehamilan, risiko tinggi dan menurunkan morbiditas dan mortalitas ibu dan perinatal. Pada pelayanan antenatal petugas kesehatan akan memberikan pengetahuan pada ibu apa yang harus ibu lakukan pada masa kehamilannya sehingga ibu dapat semaksimal mungkin menjaga kehamilannya baik dari segi nutrisi, olahraga dan pola istirahat (Hidayah, 2014).

Pada masa kehamilan ibu membutuhkan olah raga ringan yang sering disebut senam hamil. Senam hamil dilakukan untuk kesejahteraan ibu dan bayi. Hasil penelitian American Journal of Obstetric and Gynecolog, menunjukkan ibu hamil yang melakukan kegiatan senam cukup sering dan teratur selama masa tiga bulan (trimester) terakhir, ternyata mengalami persalinan yang tidak terlalu terasa sakit dibandingkan dengan persalinan ibu hamil yang tidak melakukan kegiatan senam selama masa kehamilan (Mariani, 2006).

Senam hamil yang saat ini banyak diajarkan kepada ibu hamil dikelas antenatal adalah prenatal gentle yoga. Yoga adalah sejenis olah tubuh, pikiran dan mental yang sangat membantu ibu hamil melenturkan persendian dan menenangkan pikiran terutama dalam trimester III. Prenatal gentle yoga selama kehamilan dapat meningkatkan berat badan lahir dan mengurangi kejadian prematur dan komplikasi persalinan (Rusmita, 2011). Penelitian Rusmita (2011), di Bandung yang meneliti Pengaruh Prenatal gentle yoga Selama Kehamilan Terhadap Kesiapan Fisik dan Psikologis Dalam Persalinan Pada Ibu Hamil TM III Di RSIA Limijati Bandung menunjukan hasil yang signifikan dimana nilai $p=0,014$ yaitu ada pengaruh senm hamil yoga terhadap kesiapan fisik dan psikologi pada ibu hamil.

Narendran dkk (2005), dari Vivekananda Yoga Reseacrh Foundation Bangalore, India 
mempelajari 169 ibu hamil yang dilatih dalam pendekatan terintegrasi untuk yoga dan dalam 166 kelompok kontrol yang menerima perawatan kehamilan secara rutin dengan memberikan pelatihan yoga termasuk latihan tehnik postur ("asana"), relaksasi, latihan pernapasan dalam ("pranayama"), dan meditasi, yang dilakukan selama 1 jam setiap hari. 14\% kelahiran yang prematur pada kelompok yoga dibandingkan dengan 29\% kelompok kontrol. Selain itu dalam suatu hasil penelitian menunjukkan bahwa yoga dan meditasi dapat mengurangi stress psikologis dan cedera fisik selama masa kehamilan dan persalinan, termasuk kecemasan dan rasa sakit. Penelitian ini bertujuan untuk mengetahui hubungan prenatal gentle yoga pada ibu hamil terhadap berat badan bayi baru lahir di Klinik RK.

\section{METODE}

Jenis penelitian ini adalah kuantitatif dengan desain quasi eksperimen yang bersifat two group post test. Populasi adalah ibu hamil primigravida dengan umur kehamilan 28-36 minggu yang memeriksakan kehamilan dan melakukan prenatal gentle yoga periode Mei sampai Juli 2021. Prenatal gentle yoga dilakukan dengan durasi 50 menit selama seminggu sekali dan dilakukan 4 kali. Sampel penelitian ibu hamil primigravida yang memenuhi kriteria inklusi dengan tekhnik purposive sampling yang berjumlah 50 orang (25 intervensi dan 25 kontrol). Penelitian ini telah lolos uji etik dengan nomor 2301/KEPK/III/2021.

Instrumen penelitian menggunakan lembar observasi frekuensi prenatal gentle yoga, lembar observasi berat badan lahir bagi kelompok intervensi. Dan lembar observasi berat badan lahir untuk kelompok kontrol. Teknik analisis data yang digunakan adalah analisis univariat, bertujuan untuk melihat gambaran distribusi frekuensi karakteristik responden. Analisis bivariat bertujuan untuk melihat hubungan variabel independen terhadap variabel dependen dengan menggunakan analisis Spearman Rho dan Mann Whitney U.

\section{HASIL}

Karakteristik responden pada tabel 1 menunjukkan bahwa umur responden pada kelompok intervensi yaitu dari 25 orang responden sebanyak 14 orang (56.0\%) berada pada kisaran umur 20 - 25 tahun, 11 orang (44.0\%) berada pada kisaran umur 26 - 30 tahun. Sedangkan pada kelompok kontrol, yaitu kelompok responden yang tidak melakukan prenatal gentle yoga, dari 25 orang responden sebanyak 10 orang $(40.0 \%)$ berada pada kisaran umur 20 - 25 tahun, 15 orang (60.0\%) berada pada kisaran umur 26 - 30 tahun.

Berdasarkan karakteristik pendidikan, pada kelompok intervensi dari 25 orang responden berpendidikan SMA dengan jumlah 4 orang $(16.0 \%)$, pendidikan diploma sebanyak 5 orang (20.0\%), dan mayoritas pendidikan sarjana sebanyak 16 orang (64.0\%). Sedangkan pada kelompok kontrol dari 25 orang responden berpendidikan SMA dengan jumlah sebanyak 5 orang $(20.0 \%)$, pendidikan diploma sebanyak 5 orang (20.0\%), dan mayoritas responden berpendidikan sarjana sebanyak 15 orang (60.0\%).

Berdasarkan karakteristik pekerjaan, pada kelompok intervensi dari 25 orang responden bekerja sebanyak 7 orang (28.0\%) dan mayoritas tidak bekerja sebanyak 18 Orang (82.0\%). Sedangkan pada kelompok kontrol, dari 25 orang responden distribusi pekerjaan responden yaitu bekerja sebanyak 11 orang (44.0\%) dan mayoritas tidak bekerja sebanyak 14 orang (56.0\%). Berdasarkan karakteristik umur kehamilan, pada kelompok intervensi dari 25 orang responden seluruhnya melahirkan pada umur kehamilan aterm (100\%). Sedangkan pada kelompok kontrol, dari 25 orang responden distribusi frekuensi umur kehamilan yaitu aterm sebanyak 17 orang $(68.0 \%)$ dan ada 8 orang (32.0\%) yang mengalami preterm. 
Tabel 1. Distribusi Frekuensi Karakteristik

Responden berdasarkan Umur, Pendidikan, Pekerjaan, dan Umur Kehamilan

\begin{tabular}{|c|c|c|c|c|c|c|}
\hline \multirow{4}{*}{$\begin{array}{c}\text { Karakteristik } \\
\text { Responden }\end{array}$} & \multicolumn{4}{|c|}{ Kelompok } & \multicolumn{2}{|c|}{ Jumlah } \\
\hline & & & $\operatorname{Resp}$ & nden & & \\
\hline & \multicolumn{2}{|c|}{ Yoga } & \multicolumn{2}{|c|}{ Tidak Yoga } & \multirow[b]{2}{*}{$\mathrm{n}$} & \multirow[b]{2}{*}{$\%$} \\
\hline & $\mathrm{N}$ & $\%$ & $\mathrm{n}$ & $\%$ & & \\
\hline \multicolumn{7}{|l|}{ Umur (Tahun) } \\
\hline $20-25$ & 14 & 56.0 & 10 & 40.0 & 24 & 48.0 \\
\hline $26-30$ & 11 & 44.0 & 15 & 60.0 & 26 & 52.0 \\
\hline \multicolumn{7}{|l|}{ Pendidikan } \\
\hline SMA & 4 & 16.0 & 5 & 20.0 & 9 & 18.0 \\
\hline Diploma & 5 & 20.0 & 5 & 20.0 & 10 & 20.0 \\
\hline Sarjana & 16 & 64.0 & 15 & 60.0 & 31 & 62.0 \\
\hline \multicolumn{7}{|l|}{ Pekerjaan } \\
\hline Bekerja & 7 & 28.0 & 11 & 44.0 & 18 & 36.0 \\
\hline Tidak & 18 & 72.0 & 14 & 56.0 & 32 & 64.0 \\
\hline \multicolumn{7}{|c|}{ Umur Kehamilan } \\
\hline Aterm & 25 & 100 & 17 & 68.0 & 42 & 84.0 \\
\hline Preterm & 0 & 000 & 8 & 32.0 & 8 & 16.0 \\
\hline
\end{tabular}

Tabel 2 menunjukkan bahwa berat badan lahir pada responden kelompok intervensi sebanyak 25 orang (100\%) lahir dengan berat badan normal yaitu 2500-4000 gram. Sedangkan pada kelompok kontrol sebanyak 18 orang (72.0\%) lahir dengan berat badan normal 25004000 gram dan sebanyak 7 orang (28.0\%) lahir dengan berat badan kurang yaitu $<2500$ gram. Hasil uji korelasi dengan korelasi Spearman's rho diperoleh nilai $p=0.004 \quad(p<0.05)$. Hal ini memperlihatkan bahwa ada pengaruh prenatal gentle yoga terhadap berat badan lahir.

Tabel 2. Pengaruh Prenatal Gentle Yoga terhadap Berat Badan Lahir

\begin{tabular}{|c|c|c|c|c|c|c|c|}
\hline \multirow{3}{*}{$\begin{array}{l}\text { Berat } \\
\text { Badan } \\
\text { Lahir }\end{array}$} & \multicolumn{4}{|c|}{ Kelompok Responden } & \multirow{3}{*}{$\mathrm{n}$} & \multirow{3}{*}{$\%$} & \multirow{3}{*}{$\begin{array}{c}P \\
\text { value }\end{array}$} \\
\hline & \multicolumn{2}{|c|}{ Yoga } & \multicolumn{2}{|c|}{ Tidak Yoga } & & & \\
\hline & $\mathrm{n}$ & $\%$ & $\mathrm{n}$ & $\%$ & & & \\
\hline $2500-4000$ & 25 & 100 & 18 & 72.0 & 43 & 86.0 & \\
\hline$<2500$ & 0 & 000 & 7 & 28.0 & 7 & 14.0 & \\
\hline
\end{tabular}

Tabel 3 dapat dilihat melalui uji perbedaan Mann Whitney $U$, terbukti adanya perbedaan yaitu berat badan bayi antara ibu yang melakukan prenatal gentle yoga dengan ibu yang tidak melakukan prenatal gentle yoga. Hasil uji statistik Mann Whitney menunjukkan nilai $p=$ $0.004(p<0.05)$ dengan nilai Mean Rank pada kelompok kontrol sebesar 29,00 yang lebih tinggi daripada Mean Rank kelompok intervensi yang melakukan prenatal gentle yoga, yaitu 22.00. Sehingga dapat disimpulkan bahwa adanya perbedaan berat badan lahir yang melakukan prenatal gentle yoga dan yang tidak melakukan prenatal gentle yoga dengan nilai perbedaan sebesar 07.00.

Tabel 3. Perbedaan Berat Badan Lahir Yang Melakukan Prenatal Gentle Yoga dengan Yang Tidak Melakukan Prenatal Gentle Yoga

\begin{tabular}{lccc}
\hline Mean & \multicolumn{2}{c}{ Status Pelaksanaan } & P value \\
\cline { 2 - 3 } Rank & Yoga & Tidak Yoga & \\
\hline BBL & 22,00 & 29,00 & 0,004 \\
\hline
\end{tabular}

\section{PEMBAHASAN}

Hasil penelitian ini menunjukkan bahwa prenatal gentle yoga sangat bermanfaat bagi ibu hamil baik untuk kesejahteraan janinnya saat didalam kandungan dan saat menjalani proses persalinan, sehingga pada saat bayi dilahirkan dalam keadaan sehat dan normal. Faktor-faktor yang lain yang mempengaruhi berat badan bayi lahir antara lain umur, pendidikan, pekerjaan dan umur kehamilan.

Umur merupakan salah satu faktor yang dapat mempengaruhi proses kehamilan pada responden. Umur juga merupakan faktor yang mempengaruhi berat badan lahir. Menurut Rochjati (2003) umur ibu erat kaitannya dengan berat bayi lahir. Dalam penelitian ini, mayoritas responden berusia antara 20 - 30 tahun, dan rata-rata responden masih tergolong usia reproduksi, sehingga minat dan keinginan responden cukup besar, dan hal ini memudahkan 
peneliti dalam mengajarkan prenatal gentle yoga. Kehamilan di bawah umur 20 tahun merupakan kehamilan yang berisiko tinggi yang dapat menyebabkan angka kematian dan kesakitan 2-4 kali lebih besar dibandingkan dengan ibu yang hamil pada usia reproduksi.

Usia kehamilan yang terlalu muda menyebabkan fungsi alat reproduksi yang belum siap, peredaran darah menuju serviks dan juga uterus masih belum sempurna sehingga ini dapat mengganggu proses penyaluran nutrisi dari ibu ke janin yang dikandungnya (Manuaba, 2010). Kehamilan dibawah umur juga menyebabkan masalah psikologi. Sondari et al (2006) menyatakan bahwa masa pematangan diri terlihat ketika seseorang telah berumur lebih dari 20 tahun. Pada usia ini, perkembangan fungsi kehendak mulai dominan dan seseorang mulai dapat membedakan risiko dan manfaat atas perilaku yang berhubungan dengan kesehatan ibu dan janinnya selama kehamilan.

Prevalensi BBLR meningkat seiring dengan pertambahan umur karena terjadi perubahan pada pembuluh darah dan menurunnya fungsi hormon estrogen dan progesteron. Pertambahan umur juga semakin meningkatkan risiko hipertensi yang merupakan salah satu faktor predisposisi terjadinya BBLR (Sondari et al, 2006).

Ditinjau dari aspek psikologi bahwa usia > 35 tahun mempunyai kemampuan diri dan kematangan emosional yang lebih stabil dan mempunyai pengalaman dalam kehamilan dan perawatan bayi yang lebih baik sehingga kejadian BBLR masih dapat dicega. Umur 20-35 tahun merupakan kelompok umur ideal untuk kehamilan karena pada usia tersebut, ibu telah memiliki fisik yang cukup kuat, psikologi yang stabil dan kemampuan yabg cukup untuk mampu merawat bayi dan dirinya sendiri (Martaadisoebrata et al, 2005).

Setyaningrum (2014) menyatakan bahwa pendidikan merupakan salah satu tolak ukur status ekonomi yang mempengaruhi pelayanan kesehatan. Seorang ibu sangat memerlukan pendidikan tinggi sehingga memiliki taraf hidup yang tinggi dan mampu membuat keputusan secara mandiri tentang kesehatannya. Semakin tinggi tingkat pendidikan ibu, maka semakin tinggi pula tingkat kesadarannya sehingga semakin baik pertimbangannya dalam mengambil keputusan termasuk perilaku ibu hamil untuk mencegah BBLR dengan melakukan prenatal gentle yoga. Dalam penelitian ini, latar belakang pendidikan kelompok intervensi adalah SMA, diploma dan sarjana sehingga memiliki cukup kemampuan untuk memahami teknik dan gerakan dalam prenatal gentle yoga. Sehingga hal ini memudahkan peneliti dalam pelaksanaan prenatal gentle yoga.

Umur kehamilan merupakan salah satu faktor yang dapat mempengaruhi pelaksanaan prenatal gentle yoga. Menurut Husin, 2014 yoga dapat dilakukan oleh seluruh ibu hamil mulai dari umur kehamilan 18 minggu tetapi apabila ada gangguan atau memiliki riwayat penyakit dalam kehamilan ibu bisa melakukan prenatal gentle yoga diatas 32 minggu.

Hasil penelitian ini menunjukkan dari 25 orang (100\%) responden pada kelompok intervensi seluruhnya melahirkan bayi dengan berat badan dalam batas normal yaitu 2500-4000 gram. Sedangkan pada kelompok kontrol dari 25 orang responden hanya 18 orang (72.0\%) yang melahirkan dengan berat badan lahir normal sedangkan 7 orang (28.0\%) mengalami berat badan lahir rendah. Dan berdasarkan hasil uji korelasi Spearman's rho diperoleh nilai $p=0.004$ $(p<0.05)$.

Hal ini memperlihatkan bahwa ada pengaruh antara prenatal gentle yoga ibu dengan berat bayi lahir di Klinik RK. Hal ini sejalan dengan hasil penelitian bahwa yoga dapat meningkatkan berat bayi lahir dan menurunkan kejadian prematuritas (Husin, 2014).Narendran (2009) menyatakan bahwa yoga selama kehamilan dapat meningkatkan berat lahir dan mengurangi kejadian prematur dan komplikasi persalinan. 


\section{KESIMPULAN}

Ada hubungan antara prenatal gentle yoga dengan berat badan lahir di Klinik RK. Berdasarkan hasil analisis menyatakan bahwa ada perbedaan berat badan pada ibu yang melakukan prenatal gentle yoga dengan ibu yang tidak melakukan prenatal gentle yoga. Hal ini menunjukan bahwa melakukan prenatal gentle yoga perlu dilakukan oleh ibu hamil sehingga ibu dapat menjalankan kehamilannya dengan nyaman, juga dalam persalinannya, dan bayi yang dilahirkan pun dalam keadaan sehat dan normal

\section{REFERENSI}

Aulia. A. N. dkk. (2013). Gambaran Kepuasan Ibu Hamil Terhadap Pelayanan Antenatal Care Di Puskesmas Getasan Kabupaten Semarang .

Depkes RI. (2010). Strategi Akselerasi Pencapaian Target MDG'S 2015. http://www.target mdgs.pdf. Diakses Mei 2021

Depkes RI. (2011). Profil Kesehatan Indonesia 2010. Jakarta : Departemen Kesehatan Republik Indonesia.

Hidayah. R. (2014). Hubungan faktor internal dengan peran serta ibu hamil dalam mengikuti senam hamil. Jurnal Keperawatan Universitas Muhamadiyah Malang.

Husin. F. (2014). Asuhan Kehamilan Berbasis Bukti. Jakarta : Sagung Seto

Kemenkes RI. (2019) Profil Kesehatan Indonesia 2019. https://pusdatin.kemkes.go.id/resources/downloa d/pusdatin/profil-kesehatan-indonesia/ProfilKesehatan-indonesia-2019.pdf. Di Akses Mei $\underline{2021}$
Manuaba, I., \& Bagus, G. (2007). Ilmu Penyakit Kebidanan, Kandungan dan Pelayanan KB untuk pendidikan Bidan. EGC, Jakarta.

Mariani. J. (2006). Maternal and Perinatal Outcomes of exercise in pregnant women with chronic hypertension and previous pre eclampsi. Di unduh dari url : http://www. Hindawi.com/Journal.

Martaadisoebrata, D., Sastrawinata, S., \& Saifuddin, A. B. (2005). Bunga Rampai Obstetri dan Ginekologi Sosial. Jakarta: YBPSP.

Narendran S., Raghuram N., Sulochana G., \& Rau N.H. (2005). Efficcy Of Yoga On Pregnancy Outcome. The Journal of Alternative and Complementary Medicine, 11, 237-244.

Notoatmodjo. S. (2010). IImu Perilaku Kesehatan. Jakarta : PT Rineka Citra.

Rochjati. P. (2003). Skrining Antenatal Pada Ibu Hamil. Surabaya : Pusat Safe Mother Hood-Lab/SMF Obsgyn RSU Dr. Sutomo/Fakultas Kedokteran UNAIR.

Ruslan. K. (2013). Kesehatan Ibu Hamil. Di unduh dari URL : http/l:www.kesehatan.kompasiana.com

Rusmita. E. (2011). Pengaruh Senam Hamil Yoga Selama Kehamilan Terhadap Kesiapan Fisik dan Psikologis Dalam Persalinan Pada Ibu Hamil TM III Di RSIA Limijati Bandung. Jakarta : FIK Universitas Indonesia

Setyaningrum, S. R., Triyanti, T., \& Indrawani, Y. M. (2014). Pembelajaran di Pendidikan Anak Usia Dini dengan perkembangan kognitif pada anak. Kesmas: National Public Health Journal, 243249.

Sondari, W. D., Syamsuriputra, A. A., \& Setiadi, T. (2006). Screening of alcohol-tolerant yeast of Saccharomyces Cerev/siae. J Teknlk Kimia Indonesia, 5(2), 409-414. 